ISSN 0103-5150

Fisioter. Mov., Curitiba, v. 25, n. 2, p. 351-360, abr./jun. 2012

Licenciado sob uma Licença Creative Commons

\title{
Effects of a dual-task training on dynamic and static balance control of pre-frail elderly: a pilot study
}

\author{
Efeitos do treinamento de dupla tarefa no controle do equilíbrio \\ dinâmico e estático de idosas pré-frágeis: um estudo piloto
}

\author{
Viviane Ribeiro Targino ${ }^{[a]}$, Aline do Nascimento Falcão Freire ${ }^{[b]}$, \\ Ana Carolina Patrício de Albuquerque Sousa ${ }^{[\mathrm{c}]}$, Nícia Farias Braga Maciel ${ }^{[\mathrm{d}]}$, \\ Ricardo Oliveira Guerra ${ }^{[\mathrm{e}]}$
}

[a] MSc., Physiotherapist, Rio Grande do Norte Federal University (UFRN), Natal, RN - Brazil, e-mail: viesoft@hotmail.com

[b] MSc., Physiotherapist, Doctoral student at Rio Grande do Norte Federal University (UFRN), Natal, RN - Brazil, e-mail: linefalcao@yahoo.com.br

[c] MSc., Physiotherapist, Rio Grande do Norte Federal University (UFRN), Natal, RN - Brazil, e-mail: acapas2@hotmail.com

[d] MSc., Physiotherapist, Rio Grande do Norte Federal University (UFRN), Natal, RN - Brazil, e-mail: nicia_farias@hotmail.com

[e] Ph.D, Physiotherapist, coordinator of the Masters Program in Physical Therapy at Rio Grande do Norte Federal University (UFRN), Natal, RN - Brazil, e-mail: roguerra@ufrnet.br

\begin{abstract}
Introduction: This quasi-experimental study is justified by the need to determine the effects of an intervention strategy aimed at improving the static and dynamic balance in pre-frail elderly women. We hypothesized that dual-task training on a treadmill, compared to simple training on a treadmill,may promote statistical difference in postural control of this group. Objectives: This study aimed to verify the measures of postural control in a group of pre-frail elderly after a physical therapy intervention program based on dual-task treadmill training. Materials and methods: We selected six female pre-frail elderly subjects living in the community. The research was conducted twice a week for 45 minutes, for four weeks. The simple task training consisted only in the use of a treadmill and the dual-task training consisted on the use of a treadmill associated with visual stimuli. Only the intervention group was submitted to the dualtask training. Results: Groups showed improvements in the variables of balance in different tasks, especially on static balance. Both groups showed the most notable changes in the variables related to gait. The BBS scores and the baropodometric variables showed that the experimental group could keep all values
\end{abstract}


similar or better even one month after completion of training, unlike the control group. Conclusion: The dual-task performance had no additional value in relation to the improvement of balance in general, but we observed that the effectiveness of visual stimulation seems to occur in the maintenance of short-term balance variables.

Keywords: Elderly. Physical therapy. Balance. Gait. Cognition.

\section{Resumo}

Introdução: Este estudo quase-experimental justificou-se pela necessidade de determinar os efeitos de uma estratégia de intervenção que vise melhorar o equilíbrio em idosas pré-frágeis. A hipótese era que o treinamento em esteira tipo dupla tarefa, comparado a um treinamento simples em esteira, pudesse promover diferença no controle postural do grupo. Objetivos: Este estudo teve como objetivo verificar as medidas de controle postural em um grupo de idosos pré-frágeis após um programa de intervenção fisioterapêutica com base no treinamento em esteira tipo dupla tarefa. Materiais e métodos: Foram selecionados seis idosos pré-frágeis, do sexo feminino, residentes em comunidade. A pesquisa foi realizada duas vezes por semana por 45 minutos, durante quatro semanas. A intervenção na condição de tarefa simples consistiu no treino em esteira, enquanto a condição de dupla tarefa consistiu em treino em esteira associado a estímulos visuais. Apenas o grupo de intervenção foi submetido ao treino tipo de dupla tarefa. Resultados: Os grupos apresentaram melhoras nas variáveis de equilíbrio em diferentes tarefas, especialmente naquelas do equilíbrio estático. Ambos os grupos apresentaram as mudanças mais notáveis nas variáveis relacionadas à marcha. As variáveis de Berg e as baropodométrica mostraram que o grupo experimental manteve todos os valores similares ou melhores, mesmo um mês após a conclusão do treinamento, ao contrário do grupo controle. Conclusões: $O$ desempenho da dupla tarefa não teve nenhum valor adicional em relação à melhora do equilíbrio em geral, porém observamos que a eficácia da estimulação visual tende a ocorrer na manutenção do equilíbrio das variáveis de curto prazo.

Palavras-chave: Idosos. Fisioterapia. Equilíbrio. Marcha. Cognição.

\section{Introduction}

The current interest in the process of fragility is due to the fact that this is highly prevalent with increasing age and it confers high risk for adverse health problems, and has already been established that this process is an important risk factor for the occurrence of falls $(1,2)$. Its incidence is also an important public health problem because of their social and economic repercussions (3).

With increasing age, individuals seem to rely more on exteroceptive information and prioritize the use of vision to control the balance (4), so a deficit would directly affect the movement, since the stability and body position are constantly adjusted by optical flow and positioning cues (5).

Studies of healthy older adults showed a marked reduction in ability to perform a posture and a cognitive task simultaneously compared with young adults, and also that the ability to recover stability after an external perturbation is affected by the simultaneous achievement of a secondary task $(6,7)$.

This is probably due to an interference on the cortical attention resources even in the apparent automatic processes such as walking, contributing to falls in elderly people that already have poor balance. (7-9). This deficit associated with aging has been attributed to shrinkage of the prefrontal area of the brain, since this area is strongly related to implementation tasks such as managing multiple tasks (10).

In research on this subject, it was found that exercises in general reduce the risk of falls because they increase muscle strength and improve balance and gait (11). However, these interventions with little specificity may have limited success to improve certain aspects of the position during static and dynamic performance of functional tasks (12).

The potential importance of rehabilitation in restoring the physical capacity of the elderly, especially in relation to sarcopenia, is due to the consensus of 
the existence of its reversible nature and its direct relation with musculoskeletal performance $(13,14)$. Muscle biopsies taken before and after submaximal training programs in the elderly have shown increased oxidative capacity of muscles. (15)

The most current idea regarding the balance rehabilitation in the elderly is that the training protocols must meet some specific subsystems that contribute to postural control and which are known to be most severely affected by aging (16).

It has been reported that perhaps the use of a treadmill walking, the presence of obstacles in the way and visual stimulation might influence the deficit in dual-task related to age, especially the visual stimulation, because in the elderly body, the stability was especially connected to the notion of visual and spatial, but not to other cognitive demands (17).

Several studies have demonstrated the positive effects of training programs to walk on the muscular strength, endurance and balance in older adults (18), but none of them associated with the use of electric treadmill as a form of rehabilitation. This is surprising, since there is already scientific evidence that a critical level of gait speed is an important component to maintain functional independence in elderly and that the use of a treadmill can improve the phenomena of learning and memory - therefore, the spatial and temporal parameters and walking quality. Because of the specific and repetitive stimuli, the amount of steps spent in a given time is higher in the treadmill than in conventional therapy with walking on the ground (19).

Since many daily activities involve the association of cognitive and motor components, a motor task performed under dual-task condition could provide a better index of functional capacity compared to a motor task performed alone, under normal neurological conditions (20).

\section{Materials and methods}

\section{Participants}

The convenience sample consisted of six elderly women pre-classified as pre-frail (1), living in the community of Rocas in Natal-RN/Brazil. They were divided into two groups: experimental group $(n=3)$ and control group $(n=3)$. The mean age of the sample was $73.17 \pm 4.26$ years old. To participate in the study, it was also necessary not to present neurological disorders and not to use drugs that could bring harm to the balance; to be able to walk independently, not to present cognitive impairment or dementia with a cutoff of at least 18 on the Mini-Mental State Examination; to have good visual acuity with or without corrective lenses; to have normal blood pressure for age (21); and voluntarily agree to participate in the study.

\section{Data collection instruments}

The Berg Balance Scale (BBS) is used to assess balance, containing 14 common tasks of daily life activities related to the strength, dynamic balance and flexibility, with scores ranging from zero to four each task, with a total score of 56 . The subject who achieves less than 45 points in the scale has high risk of falling. This scale is used to assess elderly and frail patients with changes and deficits in balance regardless of age (22).

The Balance Master (Neurocom International Inc.) is a system which uses the force platforms to detect the location of the center of gravity (COG) within a pre-defined theoretical limit of stability (LOS). The system provides quantitative measures of the performance of static and dynamic balance and visual feedback of the tour and position of the COG (23).

\section{Evaluation}

Before and after the period of the intervention it was performed an evaluation of the balance by computerized posturography Balance Master in static and dynamic positions, and was also applied the Berg Balance Scale. The effects of retention of training with regard to the balance were observed one month after completion of the intervention, using the same assessment tools. In posturography, three types of tests were performed:

1) Static Testing: With the volunteers in standing position with knees extended, we recorded the percentage of body weight on each leg and the position of center of mass (COM) of its forms. This test was performed with eyes open and closed, on a firm surface and an unstable surface. 
2) Testing the limits of stability: With the volunteers in the same earlier position, we evaluated the limits of stability (LOS) to quantify the movement characteristics of the center of mass (COM), associated with the ability of each volunteer to oscillate the body in eight different directions in space according to the display of the computer screen that shows a representative signal of the COM of the volunteer with a central target and other eight peripheral targets, arranged in a circle, at angles of 45 degrees and illuminated random and individually. The peripheral targets were positioned at the level of difficulty of $100 \%$ of the LOS, calculated by the equipment based on the height of the participant. The parameters used were the speed of movement (VM), maximum excursion (ME), directional control (DC) and reaction time (RT).

3) Test Walk Across (WA): This test quantified the performance of the volunteers as they walked on foot on the platform. The WA checks the progress by measuring the length and width of steps, symmetry between the lower limbs steps and gait speed.

For all tests, three measurements were obtained and the average computed was used for analysis. For the evaluation with the Berg Balance Scale, the total score was composed of the sum of the scores of each item.

\section{Intervention}

The intervention was conducted for four weeks and each session lasted around 45 minutes twice a week. It consisted of a training using the treadmill, model Gait Trainer with the suspension, for 15 minutes, in a closed environment under controlled conditions, and the remaining time was used to perform warm-up exercises, placement of equipment and monitoring. Heart rate and blood pressure were monitored and recorded during all training sessions by a portable monitor and an analog tensiometer.

For the control group, the simple task was used only with the training on treadmill. For the experimental group, the condition of dual-task was used, that is, the participants underwent the training on a treadmill in conjunction with a visual cognitive task.
All subjects were initially submitted to an electric treadmill training without inclination to familiarize themselves with the experimental protocol, as they were instructed as to the posture of the trunk, step length and positioning of the upper limbs. A suspension system was used with a percentage of $0 \%$ body weight relief only for the safety of subjects.

The speed used in the walking was calculated during the process of familiarization on the treadmill, so that all were instructed to walk as fast as possible without getting compensation to a speed that will be that $75 \%$ of maximal heart rate (MHR) predicted for the age or the maximum comfort for the individual (13). The MHR is determined by the formula 220-age, which is widely used in current scientific literature.

Before each session of walking, it was performed five minutes of active stretching and included the slow and gradual stretching of anterior and posterior muscles of the lower limbs.

The treadmill speed was increased gradually during the initial five minutes, from zero to the level determined during the initial familiarization. The visual cognitive task performed only for the experimental group was the use of simple images added by means of data projectors to 3 feet away and immediately in front of the voluntary, for 10 minutes with 5 seconds interval between each image. The images had the form of circles of $20 \mathrm{~cm}$ diameter available in five colors: red, blue, green, black and yellow, as showed in Figure 1. The sequence of images started in the fifth minute after the start of the walk in electric treadmill and the subject should verbalize the color of the circles that were appearing on the screen.

\begin{tabular}{|l|l|l|}
\hline 1st and 2nd session & $\begin{array}{l}\text { Centered circle } \\
\text { appearing in various } \\
\text { colors }\end{array}$ & \\
\hline 3rd and 4th session & $\begin{array}{l}\text { Circle of various colors } \\
\text { arranged in various } \\
\text { directions on the screen. }\end{array}$ & \\
\hline 5th and 6th session & $\begin{array}{l}2 \text { centered circles } \\
\text { appearing in various } \\
\text { colors }\end{array}$ & \\
\hline 7th and 8th session & $\begin{array}{l}2 \text { circles of various colors } \\
\text { arranged in various } \\
\text { directions on thescreen. }\end{array}$ & \\
\hline
\end{tabular}

Figure $\mathbf{l}$ - Visual attention training protocol used in conjunction with walking on a treadmill (dual task)

Source: Research data. 
The sequence of images used was developed specifically for this research. It consisted of four stages with increasing level of difficulty, which were alternated every two days of training.

\section{Statistical Analysis}

Given the nature of this study and small sample size, the results are presented as absolute frequencies, measures of central tendency and dispersion for individual data groups. This is the analysis of demographics, social and clinical participants, as well as data concerning the evolution of participants in the studied parameters, which are expressed in the form of line graphs.

\section{Results}

The anthropometric and social characteristics of the sample, as well as their clinical variables, are shown in Table 1. The sample had a body mass index average of $28.57 \pm 4.78$. The data on educational attainment of the sample, as well as the Mini-Mental Exam, which represented the cognitive level, were within acceptable parameters for the study. Only one of the elderly reported the occurrence of falls in the last year, but has not suffered fractures or been submitted to hospitalization or medical treatment.

During the familiarization on the treadmill at the first day of evaluation, the sample had a maximum heart rate mean in $146.83 \mathrm{BPM} \pm 4.26$, with an average speed of $2.86 \mathrm{~km} / \mathrm{h} \pm 0.88$.
The fragility criteria adopted to select the sample are shown in Table 2. All participants were considered as pre-frail, even though four of them have obtained positive values for weakness in only one of the items adopted. None of them received positive score in relation to weight loss, fatigue or gait speed.

With respect to scores on the BBS, it was found that, before intervention, five of the participants were already above the cutoff point for high risk of falls (22). The control group showed an improvement of their values in the second assessment, after training,

Table 1 - Anthropometric, social and clinical variables of the study sample

\begin{tabular}{lr}
\hline Characteristics & \multicolumn{1}{c}{ Mean } \\
\hline Age & $73,17 \pm 4.26$ \\
BMI & $28,57 \pm 4,78$ \\
Schooling & $3,66 \pm 1,03$ \\
MMSE & $22,66 \pm 3,72$ \\
MHR & $146,83 \pm 4,26$ \\
TMS & $2,86 \pm 0,88$ \\
\hline & $\mathbf{f}_{\mathrm{i}}$ \\
\hline Occurrence of falls* & 1 \\
Fractures & 0 \\
\hline
\end{tabular}

Source: Research data.

Notes: $\mathrm{BMI}=$ Body mass index, calculated by the formula: $\mathrm{kg} /(\mathrm{m})^{2}$; MMSE = Mini-Mental State of Examination; MHR = Maximal Heart Hate determined from the formula of Karvonen e Cols (1957); TMV = Treadmill Maximum Speed at $75 \%$ of MHR; * $=$ In the last year.

Table 2 - Fragility Criteria in each volunteer

\begin{tabular}{lcccccc}
\hline \multicolumn{7}{c}{ Pre-frail elderly } \\
\hline Criteria & CG1 & CG-2 & CG-3 & EG-1 & EG-2 & EG3 \\
Weight loss (kg) & $\mathrm{f}_{\mathrm{i}}$ & $\mathrm{f}_{\mathrm{i}}$ & $\mathrm{f}_{\mathrm{i}}$ & $\mathrm{f}_{\mathrm{i}}$ & $\mathrm{f}_{\mathrm{i}}$ & $\mathrm{f}_{\mathrm{i}}$ \\
\hline Fatigue (score) & 0 & 0 & 0 & 2 & 0 & 0 \\
Grip strength (mean) & 2 & 2 & 2 & 2 & 2 & 2 \\
Level of physical activity (\%) & 19 & 21,6 & $11^{*}$ & $12,5^{\star}$ & $16^{*}$ & $8,3^{*}$ \\
Walking speed (mean) & $78,8^{*}$ & $74,3^{*}$ & $69,6^{\star}$ & 86,4 & 86 & $79^{*}$ \\
\hline
\end{tabular}

Source: Research data.

Note: ${ }^{*}=$ Positive criteria. One or more positive criteria characterize the elderly as a pre-frail. 
returning to the values of the first evaluation one month after completion of training. The experimental group also improved their values in the second assessment, and kept these values even after a month without intervention, as showed in Graphic 1.

Baropodometric variables of the Balance Master ${ }^{\circledR}$ are presented in Table 3, separated by groups. After training, the control group showed improvement in their values on the reaction time, movement speed, maximum excursion, balance on unstable surface with open eyes, gait speed and step symmetry and length, but only five of them remained similar during the third assessment. The experimental group showed improvement in five of the variables: balance with eyes open on a firm surface, balance with eyes open and closed on an unstable surface, step length and gait speed. All these data remained similar or better during the third assessment.

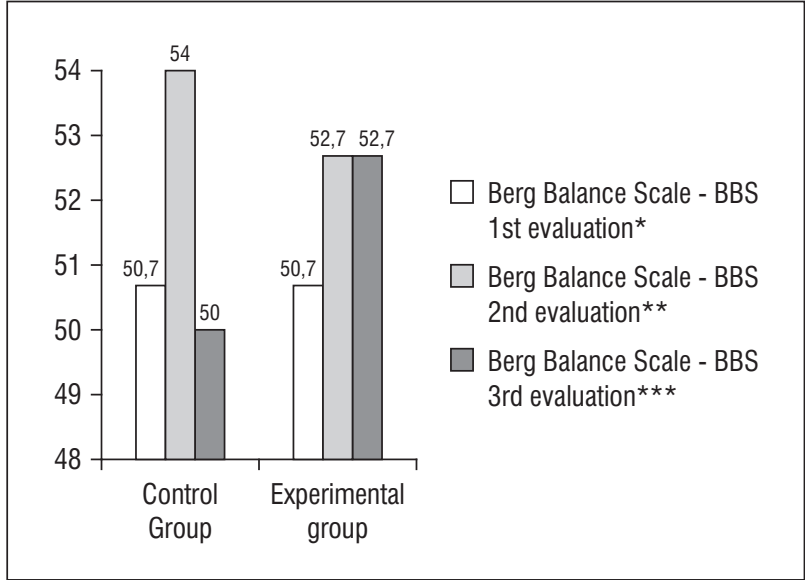

Graphic 1 - Evolution of the BBS scores at 3 moments of the research

Source: Research data.

Notes: ${ }^{*}=$ before training; ${ }^{\star \star}=$ after 8 sessions of training; ${ }^{\star \star \star}=$ one month after the end of training.

Table 3 - Baropodometric Variables in the Pre-frail and Frail groups

\begin{tabular}{|c|c|c|c|c|c|c|}
\hline & \multicolumn{3}{|c|}{ Control Group $n=3$} & \multicolumn{3}{|c|}{ Experimental Group $n=3$} \\
\hline & \multicolumn{3}{|c|}{ Mean } & \multicolumn{3}{|c|}{ Mean } \\
\hline & 1st Evaluation & 2nd Evaluation & 3rd Evaluation & 1st Evaluation & 2nd Evaluation & 3rd Evaluation \\
\hline \multicolumn{7}{|c|}{ Limits of Stability - LOS } \\
\hline $\mathrm{RT}(\mathrm{sec})$ & 1,043 & 0,737 & 0,77 & 1,213 & 1,357 & 1,15 \\
\hline MVL (deg/sec) & 3,633 & 3,967 & 3,567 & 3,433 & 2,633 & 3,49 \\
\hline EPE (\%) & 58,667 & 69,667 & 70 & 69 & 61 & 58,41 \\
\hline MXE (\%) & 77,333 & 81,667 & 85,667 & 82,667 & 76,333 & 76,08 \\
\hline DCL (\%) & 59,333 & 57,333 & 52,667 & 60,333 & 59,333 & 55,41 \\
\hline \multicolumn{7}{|l|}{ Modified CTSIB } \\
\hline Firm-E0 (deg/sec) & 0,16 & 0,2 & 0,16 & 0,16 & 0,16 & 1,16 \\
\hline Firm-EC (deg/sec) & 0,13 & 0,36 & 0,26 & 0,06 & 0,1 & 0,1 \\
\hline Foam-E0 (deg/sec) & 1,1 & 1,06 & 1,03 & 1,06 & 1,06 & 0,83 \\
\hline Foam-EC (deg/sec) & 1,73 & 2,06 & 2,26 & 1,76 & 1,63 & 1,83 \\
\hline \multicolumn{7}{|l|}{ Walk Across - WA } \\
\hline Step Width (cm) & 14,4 & 15,067 & 15,733 & 11,7 & 11,833 & 10,5 \\
\hline Step Length (cm) & 44,2 & 56,033 & 54,733 & 39,3 & 53,567 & 57,567 \\
\hline Speed (cm/sec) & 56,9 & 79,9 & 71,1 & 54,2 & 81,3 & 74,5 \\
\hline Step Symmetry (\%) & 11,333 & 9,667 & 27 & 5,667 & 18 & 12 \\
\hline
\end{tabular}

Source: Research data.

Notes: RT(sec) = reaction time; MVL = movement velocity; $E P E=$ endpoint; $M X E=$ Maximal Excursions; $D C L$ = Directional Control; Firm$\mathrm{EO}=$ eyes open on a firm surface; Firm-EC $=$ eyes closed on a firm surface = Foam -EO: eyes open on a unstable surface; Foam-EC = eyes closed on a unstable surface; Modified CTSIB = clinical test of sensory interaction on balance; Step Length Symmetry = indicating if the step length on one side is longer than step length on the other side. If there is no difference, the score will be zero. 


\section{Discussion}

This study aimed to verify the effects of dual and simple task training on postural control measures of pre-frail elderly living in community, and also the existence of these effects one month after completion of training. These effects were evaluated separately in each group and it was not performed any type of correlation or comparison between groups, since the small sample did not allow the use of statistical tests for comparison. We preferred to use the analysis of individual parameters as a means of checking the effects of training.

Over the last decade, different forms of postural assessment have been conducted in the elderly, including checking the influence of cognitive tasks on balance $(6,24-26)$. Some types of preventive training for falls in the elderly have also been proposed to improve the variables related to balance $(27,28)$. This study differential was the fact that it used electric treadmill for gait training, instead of conventional training on the ground. Moreover, we associate the visual stimulation, through a program of figures and colors, in order to promote a functional and multitasking training, exciting and brief.

It is known that the elderly, even the community ones, have a high level of inactivity, which generates changes in their physical and mental health, and even anticipates the occurrence of diseases associated with senescence. The interest in this research occurred exactly by the evidence that the fragility itself is potentially reversible (1), the prevention may indeed have influenced on some aspects of the fragility and if it starts in preclinical stages, the results are better.

The aerobic training programs generally recommend that asymptomatic elderly train with approximately $60 \%$ of maximum heart rate (MHR) predicted for age (29), but during the preliminary phase of this study we noted that, normally in a resting state, the elderly already had his heart frequency in this percentage, which forced us to raise up to $75 \%$ of MHR maximum intensity of training, ensuring the maintenance of the security level for cardio aerobic exercise in the elderly (13).

All participants were able to complete, without complications, $100 \%$ of practice time on the treadmill in all eight sessions. It should be noted that although the participants have mentioned, during the initial interview, the presence of hypertension condition under drug control, during the assessment and training they did not present changes in blood pressure levels beyond the safe limit.

The rate of displacement of the center of gravity (COG), represented by the Modified CTSIB test, is the relationship between the distance traveled by the COG and the oscillations of the individual generating scores. Lower scores represent improvement or increase of the stability. The LOS test quantifies the maximum distance a person can intentionally displace their center of gravity in one direction without losing balance, stepping, or reach out for assistance. We interpreted the values as the accuracy of the movement toward the target. The variable EPE provides a measure of how much the patient has the ability to move toward the target. Conversely, the MXE tells us how far the patient might actually move its COG. Theoretically, the EPE and MXE should be the same or very similar.

The equilibrium considered normal includes the ability to remain standing in various situations. Changes in Modified CTSIB variables in Table 3 suggest an improvement or maintenance of static balance, even in situations where visual information was unavailable. The variables related to situations where the surface is unstable, i.e., the test in which feet were on the foam surface showed a trend toward improvement or maintenance of the balance after training, suggesting that training on a treadmill, especially the dual-task type, may provide an appropriate biomechanical and sensory challenge, improving the balance of the elderly.

Although only one group has presented better values of LOS in the second assessment, this fact does not exclude the existence of a protective effect of this training for falls in the elderly, since after training these values were close to the ones of the second assessment, even in the experimental group. As this test only verifies the displacement of the COG, we can say that for the elderly, which generally have a greater reliance on hip muscles for balance, especially during movements of the body forward or backward (30), the movements using the strategy of the hip have been eliminated, providing greater credibility to the data. As groups showed improvements in the variables of balance in different tasks, only the results of this research cannot confirm that these types of training affect one or another kind of balance, which has been verified by other researches which found that training gait on a treadmill really 
improves balance-related falls, but there are no direct relationship between the dynamic balance while walking and static balance while standing upright (31). Beyond this fact, we considered that the groups, although homogeneous with respect to the degree of fragility and on the BBS scores, individuals had distinct physical and psychological characteristics, which may have somehow influenced the results of the baropodometry.

Aging is associated with loss of muscle mass (sarcopenia) with an associated reduction in maximal muscle strength, thereby making the elderly with balance impaired and fear of falling develop a strategy to voluntarily adapt their walk, reducing the step length as a compensation mechanism, also reducing the walking speed and minimizing the impulse of the COG. (32). Also in Table 3, after training, both groups showed the most notable changes in the variables related to gait, especially the length and speed, allowing us to infer the importance of a programmed gait training on a treadmill under conditions of speed and gait pattern controlled individually.

Considering the results with absolute values in this study, we verify that the dual-task performance had no additional value in relation to the improvement of balance in general, but we could observe that the effectiveness of visual stimulation occurred in the maintenance of short-term balance variables, confirmed by the BBS and baropodometry, regardless of the type of test performed one month after training. However, we can still infer that the balance and gait pattern disorders, being reversible with a motor or dual-task training, could also be indirectly reducing the risk falling among elderly people, even among the elderly in an advanced stage of weakness, bearing in mind that visual information, although very relevant, is not the only critical factor for falls in the elderly.

This study limitation is that the volunteers were aware they were receiving the intervention to check the effects on balance. Another possibility of bias in this study, with respect to improvements in the variables observed at the post-training evaluations, may have been an influence of excessive attention and motivation of volunteers. This motivation factor had already been found in previous studies (33). Moreover, the proposition of tasks without giving priority (34) to one or another task did not allow us to clearly detect any interference.

Because it is a quasi-experimental study, we recognize its limitations, especially the sample power. We could see that the results of training on a treadmill in a brief term and associated with visual stimulation, in laboratory conditions, tend to improve measures of postural control in pre-frail elderly women, but its effectiveness when carried out with the clinic usual practice may not yet be confirmed. A specific treadmill program to prevention and restoration of balance in pre-frail elderly seems to help reducing the probability of falls occurrence.

It would be necessary to carry out a similar study with a larger number of subjects and a longer time to exclude the possibility of a ceiling effect in this study, and also to assess the post-treatment longterm effects to determine the degree of retention and learning.

\section{References}

1. Fried LP, Tangen CM, Walston J, Newman AB, Hirsch C, Gottdiener J, et al. Frailty in older adults: evidence for a phenotype. J Gerontol A Biol Sci Med Sci. 2001; 56(3):M146-56.

2. Puts MT, Lips P, Deeg DJ. Sex differences in the risk of frailty for mortality independent of disability and chronic diseases. J Am Geriatr Soc. 2005;53(1):40-7.

3. Lord SR, Menz HB, Tiedemann A. A physiological profile approach to falls risk assessment and prevention. Phys Ther. 2003;83(3):237-52.

4. Redfern MS, Yardley L, Bronstein AM. Visual influences on balance. J Anxiety Disord. 2001;15(1-2):81-94.

5. Nomura Y, Mulavara JA, Richards RB, Bloomberg J. Optic flow dominates visual scene polarity in causing adaptive modification of locomotor trajectory. Brain Res Cogn Brain Res. 2005;25(3):624-31.

6. Brauer SG, Woollacott M, Shumway-cook A. The interacting effects of cognitive demand and recovery of postural stability in balance-impaired elderly persons. J Gerontol A Biol Sci Med Sci. 2001;56(8): M489-96.

7. Bloem BR, Valkenburg VV, Slabbekoorn M, Willemsen MD. The multiple tasks test development and normal strategies. Gait Posture. 2001;14(3):191-202.

8. Beauchet O, Berrut G. Gait and dual-task: definition, interest, and perspectives in the elderly. Psychol Neuropsychiatr Vieil. 2006;4(3):215-25. 
9. Shumway-Cook A, Woollacott M, Kerns KA, Baldwin M. The effects of two types of cognitive tasks on postural stability in older adults with and without a history of falls. J Gerontol A Biol Sci Med Sci. 1997;52(4): M232-40.

10. Gunning-Dixon F, Raz N. Neuroanatomical correlates of selected executive functions in middle-aged and older adults: a prospective MRI study. Neuropsychologia. 2003;41(14):1929-41.

11. Park H, Kim KJ, Komatsu T, Park SK, Mutoh Y. Effect of combined exercise training on bone, body balance, and gait ability: a randomized controlled study in community-dwelling elderly women. J Bone Miner Metab. 2008;26(3):254-9.

12. Carter ND, Kannus P, Khan KM. Exercise in the prevention of falls in older people: a systematic literature review examining the rationale and the evidence. Sports Med. 2001;31(6):427-38.

13. Nóbrega ACL, Freitas EV, Oliveira MAB, Leitão MB, Lazzoli JK, Nahas RM, et al. Posicionamento oficial da Sociedade Brasileira de Medicina do Esporte e da Sociedade Brasileira de Geriatria e Gerontologia: atividade física e saúde no idoso. Rev Bras Med Esporte. 1999;5(6):207-11.

14. Silva TAA, Frisoli A Jr, Pinheiro MM, Szejnfeld VL. Sarcopenia associada ao envelhecimento: aspectos etiológicos e opções terapêuticas. Rev Bras Reumatol. 2006;46(6):391-97.

15. Thomas EE, De Vito G, Macaluso A. Speed training with body weight unloading improves walking energy cost and maximal speed in 75- to 85-year-old healthy women. J Appl Physiol. 2007;103(5):1598-1603.

16. Hatzitaki V, Amiridis IG, Nikodelis T, Spiliopoulou S. Direction-induced effects of visually guided weightshifting training on standing balance in the elderly. Gerontology. 2008;55(2):145-52.

17. Bock OL. Dual-task costs while walking increase in old age for some, but not for other tasks: an experimental study of healthy young and elderly persons. J Neuroeng Rehabil. 2008;5(1):27.

18. King AC, Taylor CB, Haskell WL, Debusk RF. Influence of regular aerobic exercise on psychological health: a randomized, controlled trial of healthy middle-aged adults. Health Psychol. 1989;8(3):305-24.
19. Hesse S. Treadmill training with partial body weight support after stroke: a review. NeuroRehabilitation. 2008;23(1):55-65.

20. Haggard P, Cockburn J, Cock J, Fordham C, Wade D. Interference between gait and cognitive tasks in a rehabilitating neurological population. J Neurol Neurosurg Psychiatry. 2000;69(4):479-86.

21. V Diretrizes brasileiras de hipertensão arterial. 2007 [acesso 15 jun. 2009]. Disponível em: http://www. nefrologiaonline.com.br/Diretrizes/V_Diretrizes_ Brasileiras_de_Hipertensao_Arterial.pdf.

22. Berg KO, Wood-Dauphinee SL, Williams JI, Maki B. Measuring balance in the elderly: validation of an instrument. Can J Public Health. 1992;83 Suppl 2: S7-11.

23. Ben Achour Lebib S, Missaoui B, Miri I, Ben Salah F-Z, Dziri C. Rôle du Neurocom Balance Master ${ }^{\circledR}$ dans l'évaluation des troubles de l'équilibre et du risque de chute chez le sujet age. Ann Readapt Med Phys. 2006; 49(5):210-7.

24. Liu-Ambrose T, Katarynych LA, Ashe MC, Nagamatsu LS, Hsu CL. Dual-task gait performance among community-dwelling senior women: the role of balance confidence and executive functions. J Gerontol A Biol Sci Med Sci. 2009;64(9):975-82.

25. Teixeira PPS, Voos MC, Machado MAS, Castelli LZ, Valle LER, Piemonte EP. Interferência mútua entre atividade visual e atividade motora em jovens e idosos. Fisioter Pesq. 2008;15(2):142-8.

26. Kang HG, Costa MD, Priplata AA, Starobinets OV, Goldberger AL, Peng C-K, et al. Frailty and the degradation of complex balance dynamics during a dual-task protocol. J Gerontol A Biol Sci Med Sci. 2009;64(12): 1304-11.

27. Zambaldi PA, Costa TABN, Diniz GCLM, Scalzo PL. Efeito de um treinamento de equilíbrio em um grupo de mulheres idosas da comunidade: estudo piloto de uma abordagem específica, não sistematizada e breve. Acta Fisiatr. 2007;14(1):17-24.

28. Silsupadol P, Siu KC, Shumway-Cook A, Woollacott MH. Training of balance under single and dual-task conditions in older adults with balance impairment. Phys Ther. 2006;86(2):269-81. 
29. Mangione KK, Axen K, Haas F. Mechanical unweighting effects on treadmill exercise and pain in elderly people with osteoarthritis of the knee. Phys Ther. 1996;76(4):387-94.

30. Hatzitaki V, Amiridis IG, Arabatzi F. Aging effects on postural responses to self-imposed balance perturbations. Gait Posture. 2005;22(3):250-7.

31. Shimada H, Obuchi S, Kamide N, Shiba Y, Okamoto M, Kakurai S. Relationship with the dynamic balance function during standing and walking. Am J Phys Med Rehabil. 2003;82(7):511-6.

32. Thomas EE, De Vito G, Macaluso A. Speed training with body weight unloading improves walking energy cost and maximal speed in 75- to 85-year-old healthy women. J Appl Physiol. 2007;103(5):1598-603.
33. Huang S-C, Lu T-W, Chen H-L, Wang T-M, Chou L-S. Age and height effects on the center of mass and center of pressure inclination angles during obstacle-crossing. Med Eng Phys. 2008;30(8):968-75.

34. Woollacott M, Shumway-Cook A. Attention and the control of posture and gait: a review of an emerging area of research. Gait Posture. 2002;16(1):1-14.

Received: 04/12/2011

Recebido: 12/04/2011

Approved: 08/01/2011

Aprovado: 01/08/2011 